\title{
Telemedicine in the USA
}

\section{An overview}

\author{
Joseph E. Lovett and Rashid L. Bashshur
}

The authors examine the development and use of telecommunications technology in the provision of health services and in that context discuss policy formulation relating to technological innovation in health care. In the course of their examination, they consider the nature of the major challenges facing health care delivery that are amenable to responses in telecommunications technology. present selected findings from telemedicine studies in the light of these challenges, and offer a set of policy recommendations.

Rashid L. Bashshur is Professor of Medical Care Organization in the Department of Medical Care Organization, The School of Public Health, University of Michigan, Ann Arbor. Joseph E. Lovett is a PhD candidate in the Department of Medical Care Organization of the University of Michigan and Corporate Staff Consultant to the Sisters of Mercy Health Corporation, 28550 Eleven Mile Road, Farmington Hills, MI 48018, USA.

This article is an edited version of a paper presented to the Governor's Conference on the Impact of Science and Technology on the Quality of Life in Michigan, 4 April 1978.

Support for Dr Bashshur's research on telemedicine has been through the RANN programme of the National Science Foundation. At various times opportunities, support, and assistance continued on page 4

\section{Challenges to health care delivery}

Challenges to the realization of objectives in health care delivery stem from the structural and functional characteristics of the delivery system itself. Among the most significant of these are: inaccessibility to care; shortages in human health resources; the uneven distribution of resources; rising costs; and the uneven levels of the quality of care.

The provision of accessible care for all citizens is a stated national health policy goal in the USA. The origins of current inaccessibility lie in market and normative shortages in the supply of resources, and to social institutionalization or physical incapacity. Geographical, temporal, and socio-organizational factors must also be taken into account, and are commonly indicated by the unavailability of a source of care and by the effort and costs required to reach care. ${ }^{1}$

For some segments of the rural population, medical care services of any kind are not readily available. Sparse populations, widely dispersed, are often unable to support the practice of full-time physicians, let alone specialists. The lack of cultural and recreational amenities, professional isolation, lack of supportive services, and other disincentives, serve further to discourage physicians from working in rural areas.

The often long distances between population centres in rural areas, the lack of developed public transportation systems, marginal roads, and the uneven distribution of providers in relation to the population, all serve to increase the costs of reaching care.

Social institutionalization and physical disability can also cause even nearby care to be effectively unavailable. Indeed, physical disability constitutes a major barrier to care for the bedridden. Residents in prisons. nursing homes, juvenile detention centres, and institutions for people with emotional and mental disabilities, suffer substantially from inaccessible care, as is reflected by their lower levels of health.

Such shortages in numbers and maldistribution are two aspects of health resources which are often reflected in client-borne costs of reaching care. They are also likely to be reflected in inadequate quantities of care, and possibly in lowered quality of the care that is received. Perhaps no aspect of the problem of supply in health services is as great as that of human health resources. There is both a market and normative shortage of primary care physicians and other 
continued from page 3

have been provided by the Indian Health Service, The National Aeronautics and Space Administration, the Department of Medical Care Organization, and the School of Public Health of the University of Michigan.

'Joseph E. Lovett, R.L. Bashshur and G.W. Shannon. Accessibility to telemedicine satellites: expectations and achievements', paper presented at Second Workshop on Telemedicine, Tucson, Arizona. 4-5 December 1975: Gary W. Shannon, Impact of telemedicine on accessibility: concepts and measurement', in R.L. Bashshur, P.A. Armstrong and Z.I. Youssef (eds), Telemedicine: Explorations in the Use of Telecommunications in Health Care, Charles C. Thomas, Springfield, III, 1975 , pp 192-215. primary care providers. There is an excess of specialist physicians and these specialists are geographically concentrated in centres of high population density, or where there is a high level of technological and organizational support.

In medically underserved areas, per capita use of health services, particularly primary care services, is generally lower; the ratio of unattended to attended illnesses is higher. When illnesses are treated, their greater severity is reflected by longer hospital stays and higher total costs for the illness. Hence, there is often inappropriate use of existing resources due to the lack of primary care providers. This is illustrated by the higher rates of hospitalization per capita in rural areas.

The quality of care delivered when there are shortages of personnel suffers from dilemmas faced by the physician. Rural physicians in particular find themselves confronted with both diagnostic and treatment dilemmas. In contrast to urban areas, a diagnosis may be reached with inadequate consultation and greater uncertainty. Treatment may be undertaken despite lower skill levels in light of the alternative costs to the patient. These limitations may also be attributable to the physician's isolation from the mainstream of current medical thinking.

The large initial capital expenditures required for many current biomedical technologies, the high levels of utilization necessary to justify them, and their dependence on the presence of other technologies, highly skilled personnel, and organized facilities have resulted in increasing centralization of resources. One consequence of such centralization is decreased accessibility to patients.

The essence of quality in medical care is the application of normative standards for the practice of medicine based on prevailing knowledge. Uneven or incomplete diffusion of medical technology and knowledge has resulted in widely differing standards of quality. Thus, the task of maintaining and improving the quality of care depends largely on efforts to continue medical education, performance monitoring through peer review and evaluation, and the rapid dissemination and evaluation of medical knowledge. These nceds are particularly acute in the case of rural, isolated physicians and, as pointed out above, are sometimes the reason why physicians will not practice in rural areas.

Shortages in primary care physicians and the rising costs of care have been addressed by a policy which facilitates the use of lowerpriced nurse practitioners and physician assistants. It has been demonstrated that, under specific conditions of supervision, non-MD providers can deliver an acceptable quality of care. The achievement of the labour-saving benefits of non-MD providers while maintaining the quality of care requires adequate systems of communication and control between physician and non-physician. To date, these experiments have been successful primarily in group practices where physician and non-physician provider are close to each other. Increasing the distance between the two reduces accessibility to each other, reduces communication and control, and may subsequently reduce the quality of performance.

\section{Telemedicine as a response}

Telemedicine has been suggested as one technological response to 
2 Rashid L. Bashshur, and J. Lovett, 'An assessment of telemedicine: results of the initial experience', paper presented at 1976 Scientific Meeting of the Aerospace Medical Association, Miami, Florida, 10 May 1976. Revised version subsequently published in: Aviation, Space, and Environmental Medicine, Vol 48, No 1. 1977, pp 65-70; Joseph E. Lovett and R.L. Bashshur, 'Some observations on telemedicine and its assessment', paper presented at Second International Congress on Technology Assessment, Ann Arbor, MI, 26 October 1976.

3 Kenneth T. Bird, 'Telemedicine: concept and practice', in: R.L. Bashshur, P.A. Armstrong and Z.I. Youssef (eds) Telemedicine: Explorations in the Use of Telecommunications in Health Care, Charles C. Thomas, Springfield, III, 1975, pp 89112; Daniel Levinson, Telemedicine: some theoretical speculations', paper presented at Second Telemedicine Workshop, Tucson, Arizona 4-5 December 1975

4 Maxine L. Rockoff. 'An overview of some technological/health care system implications of seven exploratory broadband communication experiments'. IEEE Transactions on Communications COM-23, January 1975, pp 20-30.

${ }^{5}$ Gordon T. Moore, et al, 'Comparison of television and telephone for remote medical consultation', The New England Journal of Medicine, Vol 292, No 14, 3 April 1975, pp 792-732; Roger G. Mark and T.R. Willemain, Preliminary evaluation of the nursing home telemedicine project', paper presented at Second Workshop on Telemedicine, Tucson, Arizona, 4-5 December 1975.

${ }^{6}$ D.W. Conrath, al, 'Preliminary evaluation of alternbtive telecommunications systems for the delivery of primary health care to remote areas', IEEE Transactions on Communications, COM23. October 1975, pp 10-13; Dennis Foote, E. Parker and H. Hudson, Telemedicine in Alaska: The ATS-6 Satellite Biomedical Demonstration, Institute for Communications Research, Stanford University, Stanford, CA, February 1976 Contract NO1-LMO304734.

${ }^{7}$ D.W. Eastwood et al, 'Acuity, mobility, color rendition and boundaries of television observation in a system for remote supervision and direction of clinical anesthesia', paper presented at Second Annual Telemedicine Workshop. Tucson, Arizona, 4-5 December 1975; 'The Puerto Rico telemedicine system', The Institute of Social Technology, San Juan, PR, unpublished paper; Raymond L.H. Murphy and K.T. Bird, Telediagnosis: a new community health resource', American Journal of Public Health, Vol 64, No 2, February 1974, pp 113-119: Ben Park, An Introduction to Telemedicine: Interactive Television for Delivery of Health Services, The Alternative Media Center. The School of Arts, New York University, New York June 1974 many of the challenges to health care delivery described above. In brief, telemedicine is the application of telecommunications technology to the communication and control tasks of health care in consort with an organizational setting, personnel, and manner of conducting care which employs the benefits of telecommunications to transcend barriers of time and space. ${ }^{2}$ As a communications system, telemedicine represents a new mode for the production, distribution, and control of medical care data and services. ${ }^{3}$ Telemedicine also constitutes an organizational innovation, changing the form and content of the diagnostic process, as well as consultation, supervision, direct patient care, administration and management, and education and training. ${ }^{4}$

There are various technical configurations which have been categorized under the generic label 'telemedicine'. Mechanisms for communication have included telephones, ${ }^{5}$ radio, ${ }^{6}$ and television. ${ }^{7}$ The communications channels may operate in one direction or they may be interactive. Two-way communications may occur in one direction at a time (half-duplexed) or in both directions simultaneously (fullduplexed). ${ }^{8}$

Methods of transmission used include land-based telephone lines or coaxial cable, ${ }^{9}$ narrow and broadband transmission over laser ${ }^{10}$ or microwave line-of-sight stations, ${ }^{11}$ and satellite-based relay. ${ }^{12}$

The information-carrying capabilities of telecommunications channels may be as limited as single forms of analogue or digital signals, or as complex as a broad spectrum of audio, video, analogue, and digital information. Sound transmission includes voice and sound enhanced by electronic means (eg electronic stethoscopes). ${ }^{13}$ Visual images may be in black-and-white or colour, may appear as a series of snapshots being slowly displayed ('slow-scan'), or as a lifelike, moving image (broadband).

Technical enhancements of the image transmitted are possible through image intensification (contrast or colour), miscroscopy, ${ }^{14}$ magnification, split screens showing two separate images simultaneously, instant replay, and visualization under low light conditions. The image may be manipulated and controlled at the point of origin or remotely by the viewer. ${ }^{15}$ Control over the camera may include tilt, pan, and zoom. ${ }^{16}$

Telemedicine installations have been located in permanent delivery facilities, have been mobile within line-of-sight restrictions, ${ }^{17}$ or completely mobile through satellite relay.

Systems have been located in nursing homes, ${ }^{18}$ operating rooms, ${ }^{19}$ hospital clinics, ${ }^{20}$ prison health clinics, ${ }^{21}$ mobile field centres, ${ }^{22}$ ambulances, primary care offices, neighbourhood health centres, airport emergency rooms, classrooms, ships, and spacecraft.

The applications of telecommunications in medicine include linking remote physicians with each other (teleconsultation), linking provider with patient (telediagnosis), in administration and management (teleconference), and in education (educational television).

Telemedicine is also associated with the introduction and use of newer types of personnel, such as technicians for the equipment and non-MD providers for delivering care. Non-MD providers, such as nurse practitioners and physician assistants, may operate by formal protocols, relying on the telemedicine link only for consultation and direction in difficult cases. Alternatively, the on-site provider and the remote physician may operate concurrently as a team in the diagnosis 
- Thomas R. Willemain, 'Technical issues in the design of telemedicine systems', in: R.L. Bashshur, P.A. Armstrong, and Z.1. Youssef (eds), Telemedicine: Explorations in the Use of Telecommunications in Health Care. Charles C. Thomas, Springfield, III, 1975, pp 129-144.

${ }^{9}$ C. Solow, R.J. Weiss et al, 24 hour psychiatric consultation via TV', American Journal of Psychiatry. No 130, 1971, pp 1684-1687; Mark, op cit, Ref 5; Glen E. Hastings. 'Primary nurse practitioners in prison health care', paper presented at 103rd Annual Meeting of the American Public Health Association, Chicago, IIl, 18 November 1975

$10 \mathrm{~J} . \mathrm{S}$. Gravenstein, et al, 'Laser mediated telemedicine in anesthesia', Anesthesia \& Analgesia: Journal of the International Anesthesia Research Society, Vol 53 , 1974, pp 605-609.

1 Kenneth T. Bird, 'Cardiopulmonary frontiers: quality health care via interactive television', Chest, Vol 61 . 1972, pp 204-205; T.F. Dwyer, 'Telephsychiatry: psychiatric consultation by interactive television', American Journal of Psychiatry, Vol 130, 1973, pp 865869: Lockheed Missiles and Space Corporation, STARPAHC: Space Technology Applied to Rural Papago Advanced Health Care, LMSC, Sunnyvale, CA.

12 Robert T. Filep, 'Delivery of social services via satellite: needs assessment and evaluation', paper presented at Second Annual Telemedicine Workshop, Tucson, Arizona, 4-5 December 1975; R.G. Gould and Y.F. Lum (eds), Communication Satellite Systems: An Overview of the Technology, John Wiley and Sons, IEEE Aerospace and Electronic Systems Society, New York, 1976; Heather E. Hudson and E.B. Parker, Medical communication in Alaska by satellite', New England Journal of Medicine, Vol 289. December 1973, pp 1351-1356; Howard H. Hupe, 'Broadcast satellites for health care and education past, present, and future', paper presented at Second Annual Telemedicine Workshop, Tucson, Arizona, 4-5 December 1975; Robin S. Roberts, J. Pierce and S. Skene, The Moose Factory Telemedicine Program: a proposal for evaluation'. paper presented at Second Telemedicine Workshop. Tucson, Arizona 4-5 December 1975: Elizabeth Zinser, The assessment of technical feasibility. studio direction, communication patterns and user acceptance of telecommunications via satellite: a methodology and results", paper presented at Second Telemedicine Workshop, Tucson, Arizona, 4-5 December 1975.

13 Raymond L.H. Murphy, et al, 'Accuracy of cardiac auscultation by microwave', Chest. Vol 63, 1973. pp 578-581: Jon D. Wempner, Telemedicine: an initial experience', paper presented at Second Telemedicine Workshop. Tucson. Arizona. 4-5 December 1975.

14 Murpy and Bird, op cit, Ref 7. and treatment of patients, using the telecommunications link to overcome temporal and geographical distances.

Technically, organizationally, and functionally telemedicine represents a wide variety of options for health care delivery. The extent to which these options have been applied and their outcomes may be found in the evolution of telemedicine.

\section{History of telemedicine}

Telemedicine represents the confluence of two somewhat autonomous developments in telecommunications. The first source lies in the manned space flight programme and in the development of sophisticated technologies for biomedical telemetry and communication in space. The second stems from the telecommunications industry in the private sector. In medical care, much of this latter growth is reflected in the expansion of telecommunications in health data processing. ${ }^{23}$

The development and demonstration of the capabilities of telecommunications equipment for remote biomedical telemetry were major achievements of the space programme. Initially, NASA's scientists were concerned with the physiological effects of zerogravity on astronauts. Initial constant monitoring of heart rate, blood pressure, respiration rate, temperature, and other functions was consequently reduced to periods of high stress or activity. ${ }^{24}$ Longer flight times and anticipation of continuously staffed orbital stations led NASA to develop telemedical capabilities for diagnosing and treating in-flight medical emergencies, systems for maintaining health levels, and capabilities for biomedical research and experimentation. Direct application of experience and development in space research can be found in medical care today. One of the best examples is the widespread use by paramedical teams of the cardiac monitoring and resuscitation package developed by NASA.

However, telemedicine is not solely a descendent of the space programme. Even before television became widely available on a commercial basis, closed-circuit transmission of surgical procedures and classroom instruction via CATV were to be found in medical schools and hospitals. By 1960, the first interactive video link, providing two-way voice and visual contact, was established between the Nebraska Psychiatric Institute in Omaha and the Norfolk State Hospital 112 miles away. ${ }^{25}$

A major consideration of these early systems was to establish what clinical functions were adaptable to telecommunications. Early efforts were concerned largely with the adaptation of commercially available equipment to the clinical setting. While the promise of telemedicine, particularly the use of interactive television, was apparent, there were also constraints. Equipment reliability and maintenance costs were significant problems. Equipment performance was such that strictly controlled studio conditions were necessary to achieve reliable transmission. These constraints made the first telemedicine programme demonstrations uncertain and the clinical encounters artificial.

Despite their uncertainties, these early programmes demonstrated that there were recognizable advantages and disadvantages in the use of telemedicine. Particular insights were gained into what organizational, technical, and staffing arrangements would result in 
optimal benefits from its use and where it could be applied most effectively. Equipment needed to be more reliable, less constraining in its operation, and less intrusive in the clinical encounter. Furthermore, it was quickly realized that new health practitioners, working with established protocols, and having the facility to communicate with remote physicians, enhanced and expanded the capabilities of the single physician. It was this model which served for nearly every telemedicine system which followed.

The criteria for optimal telemedicine systems and the conditions for their use which emerged from these initial experiences were as follows:

In settings where there were integrated systems for the delivery of medical care to multiple delivery sites.

${ }^{15}$ Eastwood et al, op cit, Ref 7.

${ }^{16}$ Weston Vivian, 'Status of video communication technology for medical care', in R.L. Bashshur, P.A. Armstrong, and Z.I. Youssef (eds) Telemedicine: Explorations in the Use of Telecommunications in Health Care, Charles C. Thomas, Springfield, III, 1975, pp 41-53: J.J. O'Neill, 'Visual communications in teiemedicine', paper presented at Second Workshop on Telemedicine, Tucson, Arizona, 4-5 December 1975; Willemain. op cit, Ref 8.

${ }^{17}$ Bird, op cit, Ref 3

${ }^{18}$ Mark and Willemain, op cit, Ref 5.

19 Eastwood et al, op cit, Ref 7.

${ }^{20}$ Dwyer, op cit, Ref 11.

2) Hastings, op cit, Ref 9; Glen E. Hastings and N. Dick, An analysis of user resistance to interactive television in prison health care', paper presented at Second International Conference on Health Care Progress and Prospects, 2425 November 1975.

22 Lockheed Missiles and Space Corporation, op cit, Ref 11.

${ }^{23}$ Maxine L. Rockoff, 'Health care communications systems', in S. Winkler (ed). Computer Communications: Impacts and Implications, Proceedings of 1 st International Conference on Computer Communications, Washington, DC, October 1972, pp 465-467.

${ }^{24}$ Sam L. Pool, J.C. Stonesifer and N. Belasco, Application of telemedicine systems in future manned space flight', paper presented at Second Telemedicine Workshop, Tucson, Arizona, 4-5 December 1975.

${ }^{25}$ C.L. Wittson and R.A. Benschoter. 'Two-way television: helping the medical centre reach out', American Journal of Psychiatry. Vol 129, No 5, 1972. pp 136139: C.L. Wittson, Nebraska initiates cross-country TV psychiatry', Educational Screen and Audiavisual Guide, 1965, pp 22-24.

${ }^{26}$ Seven projects were funded by the Department of Health, Education and Welfare, two by the National Science Foundation, and one by the Office of Economic Opportunity during this period.

${ }^{27}$ Lockheed Missiles and Space Corporation, op cit, Ref 11.

The involvement of several physicians working as a group.

- The use of non-physician providers with extended clinical functions.

- In settings where personal encounters between patient and physician were not possible by any other means.

The early stage of the development of telemedicine was characterized by the pioneering efforts of a few individuals drawing on personal and organizational resources and with little public or private financial support for their efforts. The second stage, between 1965 and 1973, consisted of a deliberate effort towards research and development of the potential of telemedicine and was spurred by the infusion of shortterm federal support. Due to the substantial capital investment required and the high maintenance costs involved, it was not possible to realize organized, comprehensive telemedicine projects except as federally supported demonstrations. ${ }^{26}$

It was expected that in three years or less it would be possible to determine whether telemedicine was a viable option for comprehensive health care delivery, how cost-effective it was compared to other delivery mechanisms, how well it would be accepted by clients and providers, and what types of links, transmission, display, and equipment would be most suitable.

While earlier findings concerning clinical aspects were reaffirmed, the hoped-for findings with respect to the more general questions of applicability, effectiveness, and efficiency were not realized. Initial costs were so high and federal support so limited that many projects cut back on the patient populations served or on the comprehensiveness of the care delivered over the system. Failures, both hardware and human, marred evaluation in many instances.

The third stage of telemedicine began around 1973, with active involvement in evaluation by interdisciplinary teams. For the first time, social scientists and specialists in medical care organization, planning, and delivery were included in the effort. The first of a planned series of national conferences brought together researchers, users, designers, and industry representatives to share experiences, plans, and findings.

During this time, a cooperative effort at a comprehensive telemedicine demonstration and evaluation was occurring which deserves special mention. The parallel developments of space research and public telecommunications were brought together in a project called 'STARPAHC' (Space Technology Applied to Rural Papago Advanced Health Care). ${ }^{27}$ 
${ }^{28}$ Kenneth E. Warner, Telemedicine in the post-evaluation era: the role of government', paper presented at Second Telemedicine Workshop, Tucson, Arizona, 4-5 December 1975.

29 Lovett and Bashshur, op cit, Ref 2.

${ }^{30}$ Roberts, Pierce and Skene, op cit, Ref 12.

${ }^{31}$ Lovett, Bashshur and Shannon, op cit, Ref 1.

32 Moore et al, op cit, Ref 5.
STARPAHC was a consortium of medical care providers and the space industry, of public and private interests. Conceived and sponsored by NASA, assembled by Lockheed Missiles and Space Corporation, managed and evaluated by the US Indian Health Service, and used and evaluated by the Papago Nation, this $\$ 3.3$ million project had several unique attributes. It used the most advanced technology available from the public and private sectors. Both hardware and human systems engineering expertise from the space programme were applied to an earthbound problem of delivering medical care services on the Papago Indian reservation. Extensive evaluation criteria, decision points, and benchmark tests were developed during the initial planning stage. Existing capabilities, such as the Indian Health Services's computer-based Health Information System, were integrated into the design. Tribal members were recruited and trained to be the front-line care providers. Finally, all relevant actors, including the potential recipients - the Papago People - were actively involved in determining the system's objectives, its basic design, the criteria for performance, and authority and responsibility for its operation.

\section{Telemedicine today}

What has emerged from the efforts in telemedicine to date? What is definitely known about its performance, reliability, and potential for resolving health care delivery problems? What insights have been gained which are relevant to policy determination with respect to its further implementation and dissemination?

One author has characterized telemedicine today as being in the 'post-evaluation phase'. ${ }^{28}$ In fact, this must be qualified as the 'posthardware evaluation phase', for our own findings indicate that telemedicine as a system has been incompletely implemented and evaluated. ${ }^{29}$

Many projects have ended as a result of the demise of federal interest and support. Others continue to function, but on a more restrictive basis and with little evaluative activity. New demonstrations and evaluations are relatively few. One major effort, with several individual projects, is being undertaken in Canada under the auspices of the Canadian Department of Communications as part of a joint US/Canadian project on communications technology satellites (CTS). ${ }^{30}$

It was the initial capability of telecommunications to overcome barriers of time and distance which appealed to those involved in health care delivery and it is with respect to improving access that the most definite conclusions can be made. The use of interactive television, combined with non-physician providers, extended the individual physician's range of communication and practice to remote locations. Via the television, a physician could visit several patients located sometimes hundreds of miles away. Satellite care centres could be distributed geographically and hence made more accessible to the population. ${ }^{31}$

As well as providing communication between client and provider, telemedicine also enhances communication among providers, resulting in increased consultation, ${ }^{32}$ daily conferences, and mutual problem-solving on demand.

While effects on access can be demonstrated, those on resource 
use, costs, and quality are less certain. Non-MD providers may increase the productivity of individual physicians. Non-MD providers and telemedicine together may distribute this enhanced productivity to a greater segment of the population, and reduce the client's costs for receiving care. One study reported that the addition of three nurse practitioners and telemedicine doubled the visit productivity of a solopractitioner with no increase in the cost per visit. ${ }^{33}$ Another study found that it was the nurse practitioner and not telemedicine which had effects on workload, costs, and management. ${ }^{34}$ It seems that initial encounters over telemedicine required more physician time and hence lower physician productivity; ${ }^{35}$ but more information was gathered and subsequent visits were shorter in duration and less frequent. $^{36}$

Great care must be taken in interpreting productivity changes reported with telemedicine systems. It has long been recognized in medical care that changing the number, types and arrangement of inputs to treatment can result in a substantially different product or output. ${ }^{37}$ The extent to which inputs are changed under telemedicine can be illustrated by the Dade County Florida Prison Telemedicine Project. In that project, input changes included introduction of nurse practitioners, definition of them as primary sources of care, development of a comprehensive set of standing orders, introduction of a problem-oriented record, initiation of medical specialty consultations, and implementation of several quality audit procedures. ${ }^{38}$

In multi-provider organizations, telemedicine seems to have consequences for clinical effectiveness and efficiency. Uncertainties with respect to diagnosis and treatment are more readily resolved when there is easy access to consultation.

Findings with respect to productivity and hence costs are mixed. Other cost considerations are even less certain. Clearly, overall costs would increase if there was heavy capital expenditure in telemedicine without any consequent change in productivity. If telemedicine were widely implemented, then the enhanced ability to meet previously unmet needs, increased diagnostic ability and case finding, and the substitution of high-priced technology for lower-cost alternatives would increase total expenditures for care. Increased use of telemedicine for primary and preventive care, where previously unavailable, would have the effect of reducing subsequent utilization of higher-priced hospital services.

As the reliability of telecommunications technology increases and the unit costs decrease, initial capitalization will become a less significant factor in the costs of telemedicine. Satellite telecommunications relay is a particularly important factor in future telemedicine costs. Already, commercial satellite rates are dropping rapidly ${ }^{39}$ The capability to handle multiple users over broadband satellite channels reduces the user cost per channel, increases utilization, and reduces the cost per hour. ${ }^{40}$ Satellite-based telecommunication is also unique in that it is the only communications medium in which increasing distance between users has virtually no effect on channel costs. ${ }^{41}$

One difficulty in interpreting the past costs of telemedicine demonstrations stems from the wasteful use of the medium's capabilities. In part, this seems to have been due to the novelty of the technology or to the specificity of the system design.

Our own findings indicate that the interactive television has all but 
42 Bashshur and Lovett, op cit, Ref 2.

${ }^{43}$ Rockoff, op cit, Ref 4, p 24.

44 Dwyer, op cit, Ref 11.

${ }^{45}$ Eastwood et al, op cit, Ref 7; Gravenstein et al, op cit, Ref 10.

${ }^{46}$ Raymond L.H. Murphy, et al, 'Accuracy of dermatological diagnosis by television'. Archives of Dermatology, Vol 105, 1972, pp 833-835.

${ }_{47}$ Murphy et al, op cit, Ref 13

48 Michael Fuchs, 'Provider attitudes toward telemedicine: preliminary findings', paper presented at Second Annual Workshop on Telemedicine, Tucson, Arizona, 4-5 December 1975.

${ }^{49}$ Ben Park, 'Communication aspects of telemedicine', in R.L. Bashshur, P.A. Armstrong and Z.I. Youssef (eds), Telemedicine: Explorations in the Use of Telecommunications in Health Care, Charles C. Thomas, Springfield, III, Ben Park and R.L. Bashshur. 'Some implications of telemedicine', Journal of Communication, Vol 25, No 3, pp 161-166, 1975.

50 Park, op cit. Ref 7.

5' Roberts, Pierce and Skene, op cit, Ref 12.

${ }^{52}$ Hastings, op cit. Ref 9.

53 Bashshur and Lovett, and Lovett and Bashshur, op cit, Ref 2. replaced the telephone as the preferred mode for communicating administrative and managerial matters. ${ }^{42}$ One observer found that EKG strips, a transcription of a narrowband physiological signal, were being pasted on a card and transmitted over television - a broadband, more expensive method. ${ }^{43}$

The qualitative consequences of the use of telemedicine cover various factors, including informational quality, the quality of performance, and outcomes. In most cases it has been demonstrated that there are qualitative changes in the amount and kinds of information conveyed by telemedicine. In the cases of psychiatric therapy, it was found that even more semantic and behavioural information was conveyed in an interactive television meeting than in face-to-face encounters. ${ }^{44}$ Certain higher-cost options, such as colour, have been found to be clinically valuable in identifying cyanotic patients under anaesthesia, ${ }^{45}$ but of marginal value in identifying dermatological lesions. ${ }^{46}$ Conversely, certain enhancements, such as electronic stethoscopes, have been found to degrade the quality of information by inserting noise or by introducing 'new' and unfamiliar information. ${ }^{47}$

From evidence to date, the quality of the performance of medical care is altered by the mediating influence of telemedicine. Physicians generally perceive that the telemedicine system does not change the way in which they practice, but it does change the nature of the treatment plans which they develop. ${ }^{48}$ The extent to which it enhances or hinders task performance in direct patient care appears to be idiosyncratic, and a function of the specific medical problem or treatment modality.

Quality of performance is a direct function of specific task performance. Observers of telemedicine encounters have reported several changes. These include subtle perceptual shifts on the part of the clinician, changes in information processing behaviour for decision making, and role changes. ${ }^{49}$

Work relationships between nurse practitioners and physicians, it has been suggested, move towards greater autonomy of the nurse, more collegial relationships, and a higher level of trust and mutual dependence for the solution of problems. ${ }^{50}$

While attempts have been made, no conclusive statement can be formulated concerning the effect of telemedicine on the quality of care as measured by outcomes. This is particularly the case with effects on health status. The Canadian Telemedicine projects have taken the position that it is unreasonable to expect to demonstrate an impact on health status as a result of telemedicine. Their position is that too many social, environmental, and other medical factors intervene to demonstrate a direct effect. Also, current methodologies and measurement of health status are seen as too coarse and insensitive to reflect any effects which the telemedicine system might have. ${ }^{51}$

One set of interesting results of studies of telemedicine quality came from the Dade County Prison Project. Using comprehensive audit and review techniques, the authors concluded that telemedicine did not improve the quality of care. They noted, however, that the use of the television/nurse practitioner system also did not result in any difference in quality compared to a face-to-face encounter between a physician and patient. ${ }^{52}$

In nearly every project to date, use of the telemedicine system has been low. ${ }^{53}$ The extent to which this has been due to rejection of the 
${ }^{54}$ Rockoff, op cit, Ref 23.

55 Rashid L. Bashshur. 'Acceptance and impact of telemedicine in a rural community:, paper presented at the Fourth Annual Telecommunications Policy Research Conference, Airlie House, Airlie, 24 April 1976; Rashid L. Bashshur. Public acceptance of telemedicine in a rural community, Biosciences Communications, Vol 4, No 1, 1978, pp 17-38; Susan A. Stevens and A. Smith, Acceptance of innovation by community leaders; telemedicine and the clinic organization in rural Maine', paper presented at Second Telemedicine Workshop, Tucson, Arizona, 4-5 December 1975; H. Ashley Weeks, 'Changing attitudes towards telemedicine', paper presented at Second Telemedicine Workshop, Tucson, Arizona, 4-5 December 1975

${ }^{56}$ Bashsur (1976) and Bashshur (1978). op cit. Ref 55: James B. Rule. 'Patient attitudes toward telediagnosis', in R.L. Bashshur, P.A. Armstrong and Z.I. Youssef (eds). Telemedicine: Explorations in the Use of Telecommunications in Health Care, Charles C. Thomas, Springfield, III, 1975, pp 216-225.

${ }^{57}$ Bashshur (1976) and Bashshur (1978), op cit, Ref 55.

58 J.M. Nilles, F.R. Carlson, P. Gray and G.J. Hanneman, The Telecommunications-Transportation Trade-off: Options for Tomorrow, John Wiley and Sons, New York, 1976.

${ }^{59}$ Lovett, Bashshur, and Shannon, and Shannon, op cit, Ref 1.

60 Hupe, op cit, Ref 12

${ }^{61}$ Sylvester E. Berki, 'Telemedicine: some economic implications', in R.L. Bashshur. P.A. Armstrong and Z.I. Youssef (eds). Telemedicine: Explorations in the Use of Telecommunications in Health Care, Charles C. Thomas, Springfield, III, 1975. pp 175-191.

62 Martin C.J. Elton, The use of field trials in evaluating telemedicine applications'. in R.L. Bashshur, P.A. Armstrong and Z.1. Youssef (eds), Telemedicine: Explorations in the Use of Telecommunications in Health Care. Charles C. Thomas. Springfield, III, 1975, pp 253-299.

${ }^{63}$ Dean J. Seibert and C.J. Sanborn, Comments on the evaluation of telemedicine', in R.L. Bashshur, P.A. Armstrong and Z.I. Youssef (eds), Telemedicine: Explorations in the Use of Telecommunications in Health Care. Charles C. Thomas, Springfield, III, 1975. pp 300-308

${ }_{64} \mathrm{~J}$. Short, E. Williams and B. Christie. The Social Psychology of Telecommunications, John Wiley and Sons, New York, 1976

${ }^{65}$ J.J. O'Neill, J.T. Nocerino and P. Walcoff, Benefits and Problems of Seven Exploratory Telemedicine Projects, The Mitre Corporation, February 1975. USDHEW Contract No HRA-106-74-

${ }^{66}$ Stevens and Smith, op cit, Ref 55.

${ }^{67}$ Rockoff, op cit, Ref 4.

${ }^{68}$ Bashstrur, op cit, Ref 2, p 70. system or to its intended use for small, disadvantaged populations is not entirely clear.

Provider acceptance of the system and its subsequent use have been found to be generally positive. ${ }^{54}$ For the potential client in the community at large, acceptance of the concept of telemedicine appears to hold only for specific care conditions, to be affected by attitudes and beliefs about technology in general, and strongly influenced by feelings about the organization in which the system was situated. ${ }^{55}$

For patients, exposure to the telemedicine system usually resulted in a shift in attitudes towards the positive, ${ }^{56}$ particularly when initial perceptions were neutral. Shifting from a negative attitude to a positive one, however, was largely determined by the patient's attitudes towards the nurse practitioner who was present during the clinical encounter. ${ }^{57}$

What generalizations can be made, then, in terms of access, personnel, costs, distributional effects, quality, and acceptance, from the findings of experiences with telemedicine? Telemedicine does present clear transportation/telecommunications tradeoffs, ${ }^{38}$ which can increase access and lower the costs of obtaining care for clients. Accessibility is a complex phenomenon in its own right, and is incompletely assessed in relation to telemedicine. ${ }^{59}$ Increased accessibility of providers to each other and of providers to sources of continuing medical education and performance monitoring through telemedicine shows a strong positive result on quality, effectiveness, and productivity. ${ }^{60}$

Productivity, costs, and the efficiency of the organization of care delivery are changed in a variety of ways by the introduction of telemedicine. There is a great need for further economic, ${ }^{61}$ clinical, ${ }^{62}$ organizational, ${ }^{63}$ and social-psychological analyses. ${ }^{64}$ One outcome is that interactive telecommunications does allow dispersed health resources to be functionally integrated, resulting in greater rationalization of the use of existing resources in new and creative ways. $^{65}$

Individual acceptance of telemedicine, on the part of clients and providers, is generally quite high. More general acceptance, in the sense of sustained use, has not been demonstrated. ${ }^{66}$

In a previous review of telemedicine, we reached the conclusion that the subject had been inadequately and incompletely assessed. ${ }^{67}$ We concluded:

There is no clear indication if telemedicine complements, supplements, or is redundant with existing organizational capabilities [in medical care delivery]. ${ }^{68}$

\section{Telemedicine and health policy}

Technological growth has moved society at an accelerating pace from the industrial age, through a post-industrial computer age. ${ }^{69} \mathrm{We}$ stand now on the brink of the 'information age'. Already, large segments of the workforce are devoted to the production, manipulation, and dissemination of information. Entire cities, such as New York and Los Angeles, are functionally specialized centres for the processing of information.

Medical care delivery has moved in pace with other changes in society in this respect, creating large gaps between theory, knowledge, and practice. $^{70}$ Preventive health and health education, areas of 
${ }^{69}$ Phillip L. Bereano (ed), Technology as a Social and Political Phenomenon, John Wiley and Sons, New York, 1976.

${ }^{70}$ Mark G. Field, 'Technology, medicine and society: effectiveness, differentiation, and depersonalization', Harvard University, Cambridge, Research Group on Biomedical Sciences, Program on Technology and Society, 1968, unpublished paper.

"James R. Sorenson, Biomedical innovation, uncertainty, and doctorpatient interaction', Journal of Health and Social Behaviour, Vol 15, December 1974, pp 366-374. increasing policy attention, are predominantly information generating and disseminating activities. Our communications capabilities in medical care are hard-pressed to keep abreast of the need to disseminate information relating to changes in biomedical science. ${ }^{71}$

The effects run even deeper in the social fabric. Problems of equity stem in large part from the differentials that exist in the availability, access, and use of information. These factors have direct relevance to health goals for society and equality of opportunity in health.

Telemedicine has been described as a 'bundle' innovation. Adoption and success of any one component are clearly contingent upon the adoption and success of the others. Moreover, there appears to be a hierarchy of importance in which the actual telecommunications technology occupies an intermediate role.

Our own research has suggested that the degree of success of the implementation and use of telemedicine is strongly influenced by the setting in which it is located. Thus, telemedicine is generally more successful where inaccessibility is important. Rural areas with widely dispersed populations, limited transportation facilities or roads, and a limited supply of providers are the most appropriate locations.

The narrow technological spectrum implemented by most telemedicine projects has limited the benefits to be realized from demonstration projects. This narrow spectrum was often a direct function of the limited capital available for initiation. Any future fundings should be sufficient to allow for single-site installation of a broad range of telecommunications capabilities as an integrated package.

Because it contains technological, organizational, functional, and staffing components, the domain of policy relevant to facilitating realization of the benefits of telemedicine is quite broad and must be considered in the formulation of policy with respect to its encouragement or containment.

Telecommunications policy has direct relevance in terms of the availability of channels for transmission, control over unauthorized and potentially dangerous cross-over from other channels, regulation over images transmitted, access rights for construction of relay stations, and requirements for ownership and reporting of broadcasting facilities in the public interest. There is a need for the assessment of current federal and state communications policy focused on telemedicine and the formulation of a specific policy with respect to the use of telecommunications in health care.

The non-MD provider occupies a pivotal role in telemedicine. Creative and productive uses of non-MD providers in telemedicine systems have been hampered by existing licensing and credentialling requirements. Policy, and consequently regulation, concerning the kinds of tasks which can be performed by non-physician providers, the nature of the supervision required, and exploitation of the potential of telemedicine for periodic, performance-based relicensing/recertification must be reviewed.

The status of reimbursement for services rendered via telemedicine remains a grey area. Neither public nor private guarantors have addressed uniformly whether or not such services should be reimbursed. While not limited to telemedicine, reevaluation of the policy of using reimbursement as a mechanism for containing technology seems justified.

Issues relating to malpractice, use of video-taped encounters in 
peer-review or in litigation, and identification of provider authority and accountability remain matters for resolution, as do the related legal/ethical issues of confidentiality and security of information broadcast over public airwaves.

Telemedicine has a significant impact on the work of health care planning and planning review. Most telemedicine installations will be multi-provider arrangements if the benefits of shared use are to be realized. A system will be used for a wide range of functions, including supervision, management, planning, direct patient care, education, and research. Clear policy guidelines must be established for evaluation of the technology's benefits and consequences and for ascertaining its need on the basis of its system-wide impact.

Limits on the degree to which one can generalize about the benefits of telemedicine have been a direct consequence of the limited populations to which it has been applied. Depending on the source of funding, telemedicine systems have been directed to institutionalized, poor, elderly, and rural-isolated populations. One result is a reasonable concern that telemedicine may become the preferred mode of delivery to the disadvantaged and lead to a two-class system of medical care. Hence, there is a need for more comprehensive delivery demonstrations applied to a broader, more representative population base.

Besides clear and consistent policy objectives for evaluation, there is a need for consistent policy concerning the support of projects. Criticism has been levelled at federal policy with respect to the extent to which it would initiate and support telemedicine demonstration/evaluation projects. Among the more sensitive there is a perception that interest and support of telemedicine flagged very quickly and was capricious in its frequency and level of funding. To some extent, findings from limited demonstrations, programmes cut short, and inadequate data were used to determine policy with regard to future support.

Fundamental to the failure to achieve complete evaluation of telemedicine was the frequent failure on the part of policy makers supporting research, of funders of projects, of providers, and of researchers to place telemedicine evaluation in the total context of health care delivery.

What the history of telemedicine has demonstrated more than anything else is the need for a single policy origin for the objectives of health care delivery, derived from a single goal for health.

Currently defined policy objectives for health care delivery rest on the foundation of more broadly defined social objectives for health and for the importance of health in the realization of individual potential and equality of opportunity to participate in society. Delivery goals include accessible, quality, affordable, and acceptable care available to all citizens who have need for it, equitably distributed, with the costs equitably borne. To the extent that telemedicine demonstrations and evaluations were derived from multiple policy objectives, some far removed from the goals of health, they failed in the effort.

\section{Telemedicine as a case example}

Telemedicine has been discussed above as a specific technology application in health care delivery. As a case example, several 
72 Telecommunications and data processing, as integrative technologies addressed to problems of communication and information processing, represent two elements of such a class.

${ }^{73}$ For example, the state of lowa Legislature has recently modified its Certificate-of-Need legislation to delegate responsibility for these functions to the University of Iowa hospitals and clinics. In the state of Michigan, with its wealth of academic and provider centres of excellence, delegation of responsibility for evaluation could be organized by classes of technology and distributed to the centres where there is greatest expertise.

74 Just as the concept of shared services is finding increasing acceptance among health care providers, shared accountability and responsibility for innovation in biomedical technology may find equal acceptance. considerations emerge which may have a more general application to policy relating to biomedical technology. The general issues are:

- Policy-based definition of relevant technologies in health care.

- The locus of responsibility for the assessment of biomedical technology.

- The need for the stimulation of new partnerships for health.

Usually, technologies applied to medical care delivery originate from biomedical research applied directly to the solution of a specific diagnostic or treatment problem. Two technological innovations which did not have their origins in biomedical research, but which have had the greatest impact on the conduct of care, are data processing and telecommunications.

Restriction and control of the introduction and use of narrowly defined, specialized biomedical technologies will continue to be necessary to control health care costs through the achievement of effective and optimum utilization. Great care must be taken, however, that, in defining policy for the control of the costs of technology, alternative cost-reducing, integrative technologies are not barred from implementation. ${ }^{72}$

Policy guidelines and requirements for the analysis, design, planning, and evaluation of technologies applied in health care must be strengthened. ${ }^{73}$ The experience with telemedicine suggests very strongly that states cannot depend upon the federal government for an exhaustive and systematic assessment of new biomedical technologies. Some federal efforts are too disjointed, responsibilities too diffused, and levels of attention and support too inconsistent. There is a greater need for states to undertake this comprehensive assessment, under the leadership of a single state organization and assisted by a consortium of governmental, industrial, academic, and health care provider participation.

The recommendation for states to take greater initiative for analysis, design, planning, and evaluation of biomedical technologies suggests further that new, creative links must be forged between entities within the state. ${ }^{74}$

All three of the above areas for consideration lead to one policy strategy which could have a significant impact on health care delivery. This effort would be the formulation of a single state-wide health information system. Following from the health goals for citizens of the state, such a system would have specific objectives for the realization of an integrated, comprehensive, and coordinated flow of management, research, planning, operations, and patient care information. Through such a system, patient referrals, continuity of care, and coordination would be facilitated and so the beginnings of a rational delivery system would emerge.

There are clear reasons why motivation for the formulation of such a system must originate from the perspective of broad policy deliberation. There are both potential benefits and potential dangers. Equity of access and the burden of costs, uniform and high-quality care, and predictable, beneficial outcomes are objectives which must be achieved through a delivery system which, while achieving distributive justice, does not infringe upon the basic process of rendering personal health services in a situation of voluntary participation by both provider and client. 